\title{
Defect evolution during annealing of deformed FeSi alloys studied by positron annihilation spectroscopy
}

\author{
K. M. Mostafa, ${ }^{1,2, a)}$ F. González Cámara, ${ }^{1}$ Roumen Petrov, ${ }^{1,3}$ P. Rodríguez Calvillo, ${ }^{4,5}$ \\ E. De Grave, ${ }^{2}$ D. Segers, ${ }^{2}$ and Y. Houbaert ${ }^{1}$ \\ ${ }^{1}$ Department of Materials Science and Engineering, Ghent University-Technologiepark 903 , \\ B-9052 Gent-Zwijnaarde, Belgium \\ ${ }^{2}$ Department of Physics and Astronomy, Ghent University, Proeftuinstraat 86, B-9000 Gent, Belgium \\ ${ }^{3}$ Department of Materials Science and Engineering, Delft University of Technology, \\ Mekelweg 2,2628 CD Delft, the Netherlands \\ ${ }^{4}$ CTM-Technologic Centre, Area of Materials Forming Processes, Manresa, Barcelona, Spain \\ ${ }^{5}$ Department of Materials Science and Metallurgical Engineering, Universidad Politécnica de Cataluña, \\ Barcelona, Spain
}

(Presented 17 November 2010; received 1 October 2010; accepted 13 October 2010; published online 18 March 2011)

\begin{abstract}
High silicon steel is widely used in electrical appliances. Alloying iron with silicon improves its magnetic performance. A silicon content up to $6.5 \mathrm{wt}$. \% gives excellent magnetic properties such as high saturation magnetization, near zero magnetostriction and low iron loss in high frequencies. Their workability is greatly reduced by the appearance of ordered structures, namely $\mathrm{B} 2$ and $\mathrm{D}_{3}$, as soon as the $\mathrm{Si}$ content becomes higher than $3.5 \mathrm{wt}$. \%. This limits the mass production by conventional rolling to this maximum percentage of $\mathrm{Si}$. In this work a series of $\mathrm{FeSi}(7.5 \mathrm{wt}$. \% Si) samples with different degrees of deformation are investigated with positron annihilation spectroscopy and optical microscopy $(\mathrm{OM})$. The influence of annealing on the concentration of defects of different deformed $\mathrm{FeSi}$ alloys has been investigated by positron annihilation lifetime spectroscopy and Doppler broadening of the annihilation radiation. OM is used to investigate the microstructure of deformed samples before and after annealing. The values of the $S$ parameter present a decrease for all studied $\mathrm{FeSi}$ alloys with the increase of the annealing temperature, being attributed to a decrease of the concentration of defects. A sudden increase of the $S$-parameter value at $600^{\circ} \mathrm{C}$ was observed for all samples, which could be related to the change of the ordering of the FeSi alloys at that temperature. At $700{ }^{\circ} \mathrm{C}$, the values of the $S$ parameter decreased drastically and starting from $900{ }^{\circ} \mathrm{C}$, they became constant. The microstructures of the alloys, investigated by $\mathrm{OM}$, show that recrystallization is completed at $900^{\circ} \mathrm{C}$ and the samples are mainly free of defects, which is in agreement with the positron annihilation lifetime data. (C) 2011 American Institute of Physics. [doi:10.1063/1.3535424]
\end{abstract}

The development of advanced techniques for materials processing requires a corresponding improvement of the materials characterization techniques and development of new ones. Positron annihilation spectroscopy (PAS) is considered to be one of the very important and promising techniques in characterizing materials. ${ }^{1}$ The method relies on the propensity of positrons to become localized at open-volume regions of a solid and the emission of annihilation gamma rays that escape the system without any interaction. These gamma quanta hold information about the electronic environment around the annihilation site. ${ }^{1}$

The binary $\mathrm{FeSi}$ phase diagram ${ }^{2}$ is shown in Fig. 1. According to the diagram, annealing of the $\mathrm{FeSi}(7.5 \mathrm{wt}$ \% $\mathrm{Si}$ ) could lead to the change of ordering from $\left(\mathrm{B} 2+\mathrm{D}_{3}\right)$ at room temperature to $\mathrm{D}_{3}$ at temperatures above $T_{c}\left(\sim 650^{\circ} \mathrm{C}\right)$, which is known as order-disorder temperature. Further increase of the annealing temperature changes the order from $\mathrm{D}_{3}$ to $\mathrm{B} 2$ and above $900^{\circ} \mathrm{C}$ the alloy is with fully disordered structure type A2. Therefore in the temperature interval between room

\footnotetext{
a) Author to whom correspondence should be addressed. Electronic mail: khaled.mostafa@ugent.be. Tel.: +32 484604521 .Fax: +329264 6697.
}

temperature and $730^{\circ} \mathrm{C}$ the size of $\mathrm{DO}_{3}$ ordered zones increases with the increase in the annealing temperature. ${ }^{3}$

The defect structure in ordered alloys is well known to be much more complicated than in pure metals. The predominant type of crystal latice defect depends on the different structures $\left(\mathrm{B} 2, \mathrm{D}_{3}\right)$ in these materials. Also, the deformation such as rolling induces many dislocations and vacancies, especially the vacancies which are not easy detectable with the classical characterization methods. For this reason powerful techniques should be used to distinguish between those different defects. ${ }^{4-6}$

The material was prepared by melting of ultralow carbon steel together with a given amount of $\mathrm{Fe}-75 \% \mathrm{Si}$ master alloy in an open-air induction furnace in order to obtain the required chemical composition presented in Table I. More details about the material preparation can be found in Ref. 7.

After hot rolling and annealing the three samples with different cold reduction were prepared and used in this study as follows: sample 1 with $2.3 \%$ thickness reduction, sample 2 with $4.1 \%$ thickness reduction, and sample 3 with $18.5 \%$ thickness reduction. The samples used for the positron annihilation measurements were annealed isochronally for $1 \mathrm{~h}$ in a 


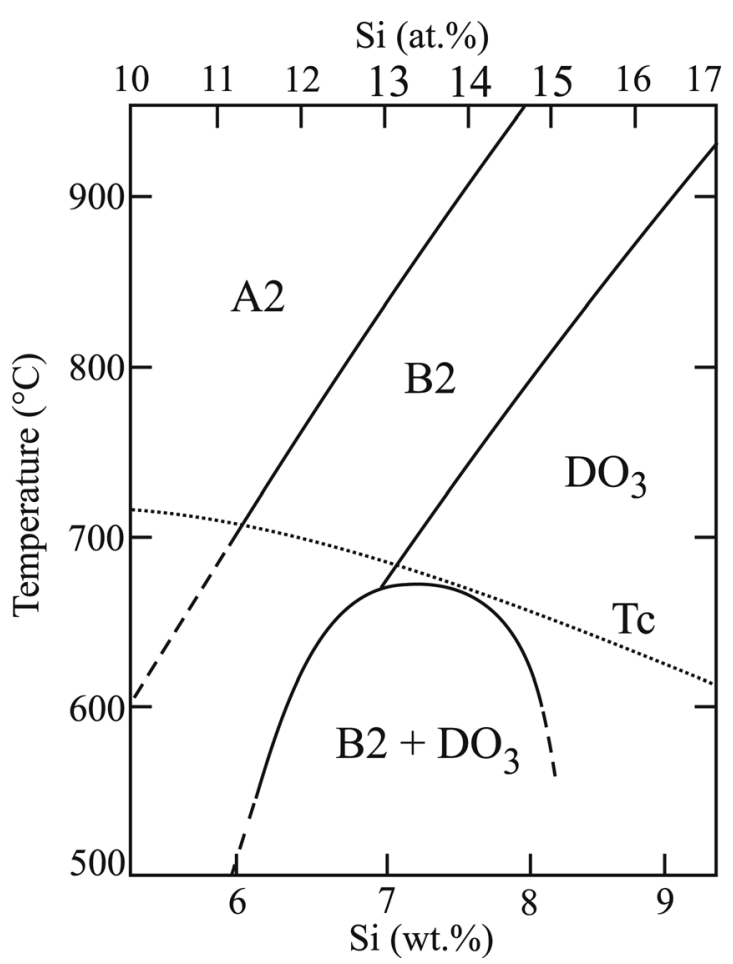

FIG. 1. Part of the binary FeSi diagram (Ref. 2).

tube furnace under vacuum at different temperatures ranging from 100 to $900^{\circ} \mathrm{C}$ and air cooled in the tube.

Positron annihilation lifetime (PALT) measurements were performed at room temperature using a fast-fast lifetime spectrometer. ${ }^{5}$ Each spectrum contained more than $10^{6}$ counts and several spectra were accumulated for each measuring point in order to ensure the reproducibility of the data. The Doppler broadening of the $511 \mathrm{keV}$ annihilation line was measured using a high purity germanium detector with a resolution of $1.2 \mathrm{keV}$ at the $514 \mathrm{keV}$ line of ${ }^{85} \mathrm{Sr}$. The results were analyzed in terms of the so-called $S$ parameter, which is defined as the area under the central part of the annihilation photopeak divided by the total area, and it is a measure of the electron momentum distribution at the annihilation site. ${ }^{1,5}$ The vacancy-type defects act as trapping sites for positrons and annihilation with low energy valence electrons at these defects results in a narrowing of the photopeak corresponding to an increase in the $S$ parameter.

To obtain the optical micrographics the standard procedure for sample preparation by grinding and polishing was used, finishing in the last step with polishing with OPS (colloidal silica suspension) in ethanol. The microstructure was revealed by etching with $4 \%$ solution of nitric acid in alcohol (Nital), which is commonly used etchant for carbon and low alloyed steels.

It is known that cold rolling induces many defects such as dislocations and vacancies in the crystal lattices of metals and alloys which make their structure thermodynamically unstable,

TABLE I. Chemical composition (wt. \%) For the Fe-Si alloys.

\begin{tabular}{lcccccc}
\hline \hline Element & $\% \mathrm{C}$ & $\% \mathrm{Si}$ & $\% \mathrm{Al}$ & $\% \mathrm{Mn}$ & $\% \mathrm{P}$ & $\% \mathrm{~S}$ \\
\hline wt. \% & 0.001 & 7.5 & 0.001 & 0.03 & 0.007 & 0.006 \\
\hline \hline
\end{tabular}

TABLE II. PALT measurement data for the $18.54 \%$ thickness reduction Fe7.5 Si alloy (sample 3).

\begin{tabular}{lccccc}
\hline \hline Sample & $\tau_{1}(\mathrm{ps})$ & $\tau_{2}(\mathrm{ps})$ & $\tau_{3}(\mathrm{ps})$ & $I_{2}$ & $I_{3}$ \\
\hline $\begin{array}{l}\text { Deformed sample } \\
3(18.5 \% \text { thickness }\end{array}$ & $75 \pm 3$ & $166 \pm 4$ & 0 & $90 \pm 4$ & 0 \\
reduction) & & & & & \\
Annealed at $600^{\circ} \mathrm{C}$ & 81 & 160 & $264 \pm 31$ & $65.4 \pm 3$ & $10.2 \pm 2$ \\
Annealed at $650^{\circ} \mathrm{C}$ & $84 \pm 3.7$ & 165 & $230 \pm 22$ & $37 \pm 2$ & $12.3 \pm 2$ \\
Annealed at $900^{\circ} \mathrm{C}$ & 107 & & & & \\
\hline \hline
\end{tabular}

i.e., with over equilibrium defects concentration. These defects have a structure that is significantly different from the structure of the "normal" crystal lattice and they could be detected and quantified via the positron annihilation lifetime. Table II represents the positron annihilation lifetime data for the FeSi alloy deformed to $18.54 \%$ thickness reduction (sample 3) and after annealing for $1 \mathrm{~h}$ at different temperatures. For the deformed sample, the positron lifetime spectra could be fitted by two distinct lifetime components ( $\tau_{1}$ and $\tau_{2}$ ) with relative intensities $I_{1}$ and $I_{2}$, respectively. The lifetime for positrons annihilated in defects $\left(\tau_{2}\right)$ is found to be around $160 \mathrm{ps}$, but the two state trapping model $^{8}$ could not be applied in the way it should be. This is probably due to the rather complex defect structure present in the material. It is important to take into consideration that the super dislocations of the $\mathrm{DO}_{3}$ phase have been detected in alloys with Si contents above 6.5 wt. $\%,{ }^{9,10}$ which could affect the analysis of the highly deformed FeSi alloys. It is known that the value of the lifetime of positrons trapped in dislocations is close or slightly below the vacancy lifetime. ${ }^{11,12}$ For this reason, it is easy to believe that the 160 ps positron annihilation lifetime value is related to vacancies trapped in the stress field around a dislocation line or in vacancies on a dislocation line. The PALT data suggested that no change of the defect type as a function of annealing time is observed at temperatures below $600{ }^{\circ}$ C. Significant amounts of thermal vacancy clustering in $\mathrm{FeSi}$ alloys are created at the annealing temperature $600^{\circ} \mathrm{C}$, and $650^{\circ} \mathrm{C}$ as shown in Table II. For the annealed sample at $600{ }^{\circ} \mathrm{C}$, a third lifetime with a value of 264 ps with intensity of $10.2 \%$ is observed, which according to Nagai et al. ${ }^{13}$ could be related to vacancy clustering in the FeSi alloy.

At $650{ }^{\circ} \mathrm{C} \tau_{3}$ becomes $230 \mathrm{ps}$ and its intensity increased to be $12.3 \%$. This longer lifetime component $\left(\tau_{3}\right)$ of $230 \mathrm{ps}$ corresponds to a cluster of four vacancies cluster in the FeSi alloy. ${ }^{13}$ After the annealing of samples at $900^{\circ} \mathrm{C}$ for $1 \mathrm{~h}$, only one lifetime component exists with a value of $107 \mathrm{ps}$, which is similar to that of the well-annealed pure Fe. This means that vacancies trapped in the stress field around a dislocation line $\left(\tau_{2}\right)$ and vacancy clusters $\left(\tau_{3}\right)$ are annealed out with the increase of the annealing temperature and the samples became mainly free of defects [concentrations in the samples are less than the lower detection limit of $\left(\sim 10^{-6}\right)$ of the positron annihilation technique]. ${ }^{13}$

The dependence of the $S$ parameter on the isochronal annealing temperature for different deformed FeSi samples is shown in Fig. 2. In the temperature range $\left(20-500^{\circ} \mathrm{C}\right)$ the $S$ parameter slightly decreases. A peak which appears at $600^{\circ} \mathrm{C}$ is due to vacancy clustering (detected by the PALT measurements) which can be related to ordering effects $\left(\mathrm{B} 2+\mathrm{DO}_{3} \rightarrow \mathrm{DO}_{3}\right)$. Viala et al. ${ }^{14}$ observed FeSi alloys with a 6.5 wt. \% Si formation of a 


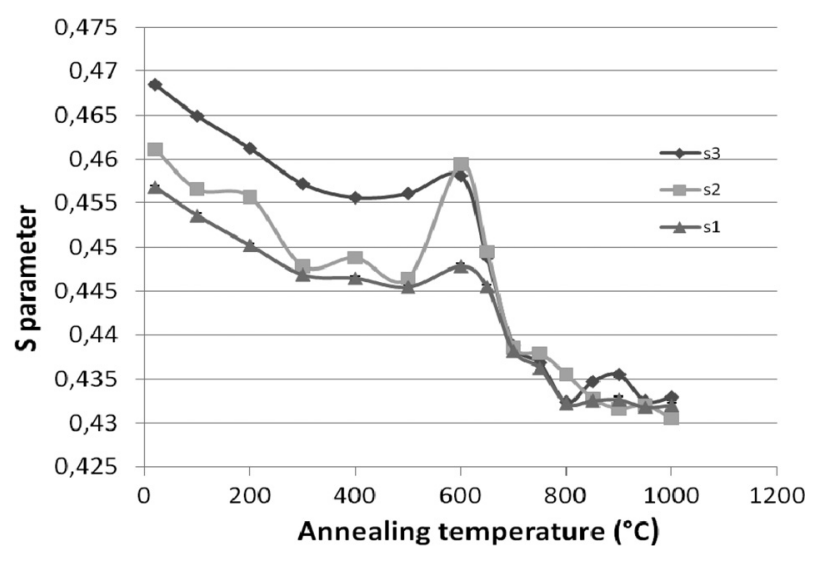

FIG. 2. The annihilation line shape parameter $(S)$ as a function of the isochronal annealing temperature of differently deformed FeSi samples [s1 with $2.3 \%$ deformation, s2 with $4.12 \%$ deformation, and s3 with $18.54 \%$ deformation (annealing time $1 \mathrm{~h})]$.

$\mathrm{DO}_{3}$ superlattice through nucleation within the existing $\mathrm{B} 2$ domains. This $\mathrm{DO}_{3}$ is formed at an annealing temperature $\sim 650^{\circ} \mathrm{C}$. Also Swann et al. ${ }^{2}$ identified the $\mathrm{DO}_{3}$ precipitates in the B2 matrix of the $6.4 \%$ Si steel when the samples were held at $600^{\circ} \mathrm{C}$ for $24 \mathrm{~h}$. These previous results show that at nearly $600^{\circ} \mathrm{C}$, the $\mathrm{DO}_{3}$ domains are formed in the $\mathrm{B} 2$ matrix of high $\mathrm{Si}$ electrical steels with $6.5-7.5 \% \mathrm{Si}$. After that, a significant decrease of the value of the $S$ parameter is observed, which indicates that defects are annealed out after the heat treatment at temperatures higher than $650^{\circ} \mathrm{C}$. Starting from the annealing temperature of $850^{\circ} \mathrm{C}$, the $S$ parameter became almost constant.

Figure 3 shows the microstructure of the FeSi alloy after deformation by rolling to a thickness reduction of $2.3 \%$ (sample 1) and $18.54 \%$ (sample 3 ) and after annealing of the deformed samples at $700{ }^{\circ} \mathrm{C}$ for $1 \mathrm{~h}$. The optical microscope images show that the heavily deformed sample (sample 3 with $18.54 \%$ thickness reduction) has a higher amount of shear bands within pancake grains elongated along the rolling direction than the low deformed one (sample 1 with $2.3 \%$ thickness reduction). Microcracks could be observed in the micrographs of the heavy deformed sample [see Fig. 3(b)]. After annealing at $700{ }^{\circ} \mathrm{C}$, the microstructure of the samples remains unchanged and the shear bands in both samples are the same before and after the annealing, which means that samples 1 and 3 are not recrystallized at all [see Figs. 3(a) and 3(b)]. The results from the optical microscopy reveal that the observed changes in the annihilation line shape parameter $(S)$ should be associated with recovery but not with recrystallization processes.

In this paper the recovery and recrystallization of a cold deformed Fe7.5\% Si alloy were studied by PAS and optical microscopy (OM). The PAS is proved to be a very sensitive technique that can detect small structural changes in the material even when the microstructural changes are not observed by OM method.

The PAS data suggested the following. The lifetime for positrons annihilated in defects $\left(\tau_{2}\right)$ is found to be around $160 \mathrm{ps}$ in the deformed samples in the temperature range

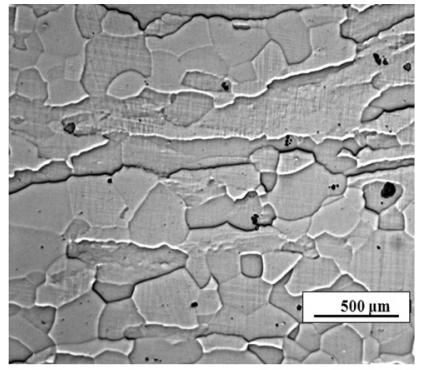

Sample 1 at room temperature

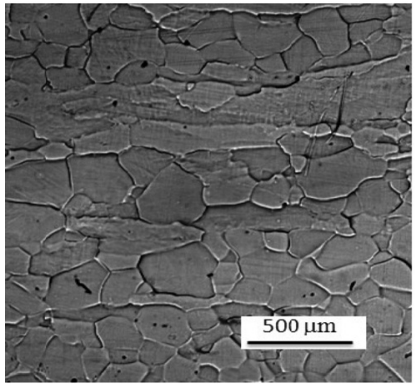

sample1 annealed at $700^{\circ} \mathrm{C}$

(a)

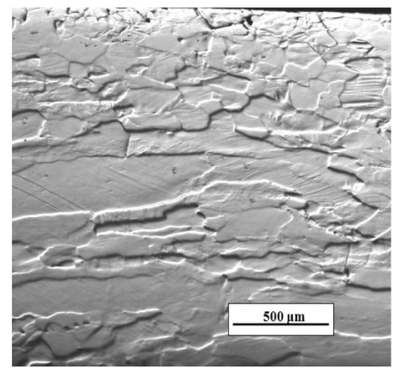

Sample 3 at room temperature

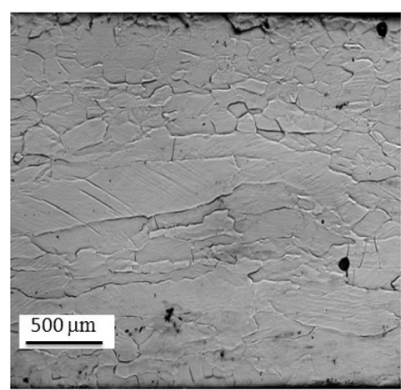

sample 3 annealed at $700^{\circ} \mathrm{C}$

(b)
FIG. 3. Light optical microstructures (OM) for the FeSi alloy: (a) sample 1 deformed to a thickness reduction of $2.3 \%$ and annealed at $700{ }^{\circ} \mathrm{C}$ for $1 \mathrm{~h}$ and (b) sample 3 deformed to a thickness reduction of $18.54 \%$ and annealed at $700^{\circ} \mathrm{C}$ for $1 \mathrm{~h}$.

$20-500{ }^{\circ} \mathrm{C}$, which is believed to be related to vacancies trapped in the stress field around a dislocation line or in vacancies on a dislocation line.

No change of the defect type with annealing is observed before $600{ }^{\circ} \mathrm{C}$. At $600^{\circ} \mathrm{C}$, vacancy clustering in the $\mathrm{FeSi}$ alloys is observed.

The dependence of the $S$ parameter on the isochronal annealing temperature shows that in the temperature range $\left(20-500^{\circ} \mathrm{C}\right)$ the $S$ parameter slightly decreases and a peak appears at $600^{\circ} \mathrm{C}$. This peak is due to vacancy clustering that can be related to ordering effects $\left(\mathrm{B} 2+\mathrm{DO}_{3} \rightarrow \mathrm{DO}_{3}\right)$, which is also detected by the PALT measurements. After that a significant decrease of the value of the $S$ parameter can be observed, which indicates that defects are annealed out after the annealing at temperatures higher than $600^{\circ} \mathrm{C}$.

${ }^{1}$ P. Asoka-Kumar and K. G. Lynn, Journal De Physique IV 5, C1-15 (1995).

${ }^{2}$ P. R. Swann et al., Met. Sci. 9, 90 (1975).

${ }^{3}$ X. Y. Zhang et al., Materials Letters 34, 85 (1998).

${ }^{4}$ K. M. Mostafa et al., Acta Physica Polonica A 113, 1471 (2008).

${ }^{5}$ R. Krause-Rehberg and H. S. Leipner, Positron Annihilation in Semiconductors (Springer, Berlin, 1999).

${ }^{6}$ P. Hautojarvi et al., Phil. Mag. 35, 973 (1977).

${ }^{7}$ P. R. Calvillo et al., Mater. Sci. Forum 550, 539 (2007).

${ }^{8}$ R. N. West, "Positrons in Solids," in Topics in Current Physics, edited by P. Hautojarvi (Springer, Berlin, 1979), Vol. 12, p. 89.

${ }^{9}$ T. Saburi and S. Nenno, Philos. Mag. 15, 813 (1967).

${ }^{10}$ K. Takita et al., Scripta Met. 7, 989 (1973).

${ }^{11}$ T. E. M. Staab et al., Materials Science 34, 3833 (1999).

${ }^{12}$ M. J. Puska et al., Phys., Condens. Matter 1, 6081 (1989).

${ }^{13}$ Y. Nagai et al., Phy. Rev. B 67, 224202 (2003).

${ }^{14}$ B. Viala et al., Mater. Sci. Eng. A 212, 62 (1996). 